\title{
José Reis e uma vida dedicada a divulgar a ciência
}

\section{José Reis: a life dedicated to disseminating science}

\author{
Marta Ferreira Abdala-Mendes ${ }^{i}$ \\ i Professora, Instituto Federal de Educação Ciência e Tecnologia do Rio de Janeiro, Campus Mesquita. \\ Mesquita - RJ - Brasil \\ orcid.org/0000-0001-5573-4317 \\ marta.mendes@ifrj.edu.br
}

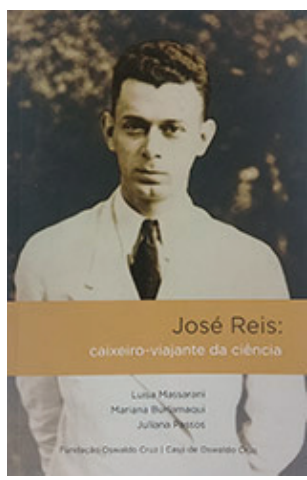

MASSARANI, Luisa; BURLAMAQUI, Mariana; PASSOS, Juliana. José Reis: caixeiro-viajante da ciência. Rio de Janeiro: Fiocruz/COC, 2018. 128p.

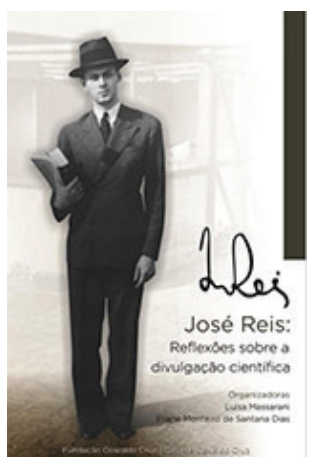

MASSARANI, Luisa; DIAS, Eliane Monteiro de Santana (org.). José Reis: reflexões sobre a divulgação científica. Rio de Janeiro: Fiocruz/COC, 2018. 236p.
Tratar sobre a história da ciência e divulgação científica no Brasil perpassa por importantes colaboradores, entre eles, sem dúvida, José Reis (1907-2002). Com uma atuação ampla e longeva no cenário científico brasileiro, aposentou-se como bacteriologista do Instituo Biológico, foi fundador e secretário-geral da Sociedade Brasileira para o Progresso da Ciência (SBPC), integrante do Instituto Brasileiro de Educação, Cultura e Ciências (Ibecc), criador e editor do suplemento "No Mundo da Ciência" e diretor de redação da Folha de S.Paulo, divulgador da ciência em diversos veículos, como nas revistas Chácaras e Quintais, Ciência e Cultura e Anhembi, e no programa "Marcha da Ciência", da Rádio Excelsior, presidente da Associação Brasileira de Jornalismo Científico (ABJC), além de um incansável ativista e incentivador pela melhoria do ensino de ciência nas escolas e da formação de futuros cientistas, promovendo o concurso "Cientistas de Amanhã" e feiras e clubes de ciências pelo país. É sobre essa trajetória que os livros José Reis: reflexões sobre a divulgação científica, de Luisa Massarani e Eliane Monteiro de Santana Dias, e José Reis: caixeiro-viajante da ciência, de Luisa Massarani, Mariana Burlamaqui e Juliana Passos, são dedicados.

Em comum, as duas obras são frutos do projeto Acervo José Reis da Casa de Oswaldo Cruz (Fiocruz), criado para promover a recuperação e preservação de todo acervo pessoal doado pela família Reis à Casa de Oswaldo Cruz/Fundação Oswaldo Cruz, em 2018, e para fomentar estudos sobre a história da ciência brasileira e da divulgação científica no país. As diferenças em cada obra encontram-se, sobretudo, pelo olhar direcionado pelas autoras ao conteúdo do acervo.

O livro José Reis: reflexões sobre a divulgação científica traz a organização de textos escritos pelo próprio José Reis sobre suas 
reflexões acerca da atividade de divulgar a ciência. As autoras reuniram 16 textos publicados em revistas do período de 1954 a 1984, além de palestras, aulas e discursos encontrados nos arquivos pessoais do cientista-divulgador (Abdala-Mendes, 2006).

Entre os textos incluídos no livro estão alguns em que José Reis, a partir de sua vivência, procurou ser mais normativo, de forma a conceituar a atividade de divulgação científica, como definir o papel social da ciência e dos diversos atores em diferentes meios, instituições e veículos. Outros textos, no entanto, são mais críticos acerca do fazer científico, do trabalho e do distanciamento do cientista em relação à sociedade e sobre a melhoria do ensino da ciência. Escritos em linguagem clara, direta e pessoal, os textos escolhidos consistem em uma fonte sobre a historicidade do cenário científico brasileiro e internacional e das mudanças conceituais e teóricas da atividade de divulgação científica.

Uma particularidade importante da obra são as notas de rodapé, em que as autoras em alguns momentos fornecem informações históricas ou registro de fontes as quais José Reis não aprofundou nos textos e, em outros, trazem explicações do próprio autor para complementar as histórias e/ou pessoas citadas.

Cada texto escolhido compõe um capítulo do livro. Ao longo dos capítulos, podemos acompanhar os argumentos construídos por José Reis para defender e justificar a divulgação científica "como útil e necessária" (Massarani, Dias, 2018, p.35); os destaques da importância de instituições (Museu Nacional, SPBC, Ibecc, CNPq) e de cientistas brasileiros e estrangeiros (Roquette-Pinto, Miguel Ozório de Almeida, Arthur Neiva, André Dreyfus, Rodolfo Von Ihering, Isaias Raw, Mauricio Rocha e Silva, Henrique da Rocha Lima, Oswaldo Frota Pessoa) para o desenvolvimento da ciência, de seu ensino e divulgação no país.

As análises e reflexões de José Reis, ao mesmo tempo, caracterizam e descrevem suas ações na divulgação científica, como por exemplo o texto sobre sua atuação na promoção do concurso "Cientistas de Amanhã" e de clubes e feiras de ciências pelo país (definidas como "revolução pedagógica" (Massarani, Dias, 2018, p.131), como também problematizam o trabalho e o campo de atuação do divulgador da ciência para "dar ... mediante lento processo de educação e não de propaganda, uma boa ideia do valor e do sentido da ciência, de suas implicações, de suas necessidades básicas" (p.41).

Ao relacionar a popularização da ciência a um projeto de educação científica para todos, José Reis resgatou, em vários momentos, o ofício do jornalista científico para "trocar a ciência em miúdos" (Massarani, Dias, 2018, p.110) e sua preocupação com a função social da divulgação científica e a melhoria do ensino da ciência. Esse aspecto não ficou centrado, apenas, em textos escritos em diferentes veículos, mas motivou ações direcionadas para o público escolar. No capítulo 10, encontramos um artigo - publicado no jornal Folha de S.Paulo, em 1964, e num livreto do Instituto de Física Teórica de São Paulo, em 1965 - em que José Reis explica o que são as feiras e os clubes de ciências, e o concurso "Cientistas de Amanhã" e o papel para "melhorar as condições do ensino em geral e despertar entusiasmo pelo estudo das ciências" (p.132), para "o progresso do ensino das ciências" (p.138), para "melhor aproveitamento de nosso potencial científico" (p.142), e o "grande cansaço, mas um cansaço feliz" (p.146), por suas participações em quase todas as feiras e concursos.

A relevância, trazida pelo autor, da função que a imprensa pode desempenhar para "compensar as nossas deficiências educacionais" (Massarani, Dias, 2018, p.115) e para 
contextualizar a ciência numa perspectiva social maior revela um paralelo com os estudos atuais no campo do jornalismo científico, que buscam um aprofundamento tanto para a credibilidade da produção jornalística em ciência como para a promoção da consciência crítica dos cidadãos acerca das implicações sociais da ciência e da tecnologia.

Já a obra José Reis: caixeiro-viajante da ciência consiste em um ensaio biográfico apoiado, diretamente, em fontes primárias do acervo particular. O acesso aos textos, documentos pessoais, livros e fotografias do cientista-divulgador permitiu às autoras enriquecer as informações já tratadas em trabalhos acadêmicos e, com isso, oferecer a sensação de intimidade com essa "estrela ... fundamental na construção da ciência brasileira e ícone da divulgação científica no Brasil” (Massarani, Burlamaqui, Passos, 2018, p.9).

Logo no início, as autoras apresentam a vida familiar e escolar de José Reis até sua entrada, aos 22 anos, como cientista contratado, no recém-criado Instituto Biológico entremeando trechos de entrevistas, depoimentos e/ou textos escritos pelo próprio em diferentes épocas. Ao nos indicar, em nota de rodapé, a presença de um original manuscrito aos 11 anos Alma infantil, dedicado aos pais (Massarani, Burlamaqui, Passos, 2018, p.11) -, as autoras vão dando pistas das preciosidades contidas no Acervo José Reis.

Por suas produções iniciais, podemos perceber como José Reis mostrava, desde jovem, aptidão e interesse pelas ciências e por escrever a respeito, tendo criado junto com seu irmão Ernani uma revista própria, Revista Carioca (Massarani, Burlamaqui, Passos, 2018, p.11), em que publicavam crônicas e poesias em letra de forma, bem como desenhos. As autoras confirmam o leitor insaciável - como ele escreveu, lia nos bondes e trens, e devorava desde Aristóteles a autores estrangeiros (p.13) -, pela presença em sua biblioteca de inúmeras obras (cerca de 12 mil) em vários idiomas e temas, que, felizmente, compõem o Acervo José Reis.

Pelos depoimentos presentes no livro, podemos constatar as dificuldades, mas também as alegrias, em se tornar um cientista num período de construção e sistematização da ciência no país. Os relatos sobre o período em que cursou a especialização do Instituto Oswaldo Cruz, em Manguinhos (Massarani, Burlamaqui, Passos, 2018, p.14), e trabalhou como cientista no Instituto Biológico (p.17) evidenciam o contexto científico na época e o contato com importantes nomes da ciência brasileira como Carlos Chagas, Olimpo da Fonseca Filho, Aristides Marques da Cunha, Arthur Neiva, Henrique da Rocha Lima, Rodolpho von Ihering e muitos outros.

Nos capítulos seguintes, acompanhamos a iniciativa de José Reis de ser mais do que um divulgador científico, e sim um verdadeiro caixeiro-viajante da ciência, como registrado no título do livro. Suas viagens pelo interior do país - desde o tempo dos estudos das doenças das aves e conversas com os criadores até as idas às feiras de ciências em vários municípios - foram importantes para disseminar e concretizar suas ideias de educação e ciência para o desenvolvimento de uma nação próspera e instruída. Suas ações coadunam com a definição de divulgação científica (Massarani, Burlamaqui, Passos, 2018, p.24) presente na obra Cientistas do Brasil: depoimentos, organizada pela SBPC em 1998. Numa definição que se mantém tão atual, José Reis destaca a importância social da divulgação científica para além do "relato dos progressos científicos" (Massarani, Burlamaqui, Passos, 2018, p.24). Mesmo tendo o objetivo de divulgar a informação científica à sociedade de forma clara, objetiva, em linguagem simples, a preocupação perpassa também pelos contextos sociais 
implícitos nessa atividade, de forma que o cidadão possa ter conhecimento e se apropriar da ciência que financia.

Merece destaque a recuperação e preservação de fotografias e documentos realizada pela equipe do Acervo José Reis, como mostra o álbum de fotos e documentos no final do livro. Trata-se de uma relevante fonte de informações biográficas e imagéticas disponibilizadas para os que pensam sistematicamente a divulgação científica como campo de pesquisa, bem como para o público leitor. Mais uma vez as autoras deixam o gostinho do acervo pessoal de José Reis, que está acessível a todos na Casa de Oswaldo Cruz/Fiocruz ou no site http://josereis.coc.fiocruz.br.

Além de homenagem a esse relevante cientista-divulgador-jornalista científico brasileiro, as duas obras configuram uma reflexão sobre a constituição da ciência brasileira e sua divulgação a partir da vida e do vasto legado de José Reis - não à toa considerado o patrono do jornalismo científico brasileiro -, bem como um material rico e minucioso para futuros estudos sobre a história da divulgação científica, a definição desse campo e produções na área.

\section{REFERÊNCIAS}

ABDALA-MENDES, Marta Ferreira. Uma perspectiva histórica da divulgação científica: a atuação do cientista divulgador José Reis (19481958). Tese (Doutorado em História das Ciências e da Saúde) - Casa de Oswaldo Cruz/Fiocruz, Rio de Janeiro, 2006.

MASSARANI, Luisa; BURLAMAQUI, Mariana; PASSOS, Juliana. José Reis: caixeiro-viajante da ciência. Rio de Janeiro: Casa de Oswaldo Cruz/ Fiocruz, 2018.

MASSARANI, Luisa; DIAS, Eliane Monteiro de Santana (org.). José Reis: reflexões sobre a divulgação científica. Rio de Janeiro: Casa de Oswaldo Cruz/Fiocruz, 2018. 